\title{
As bichas e os bofes na crise do sistema penitenciário*
}

\author{
Vanessa Sander**
}

\section{Resumo}

O artigo analisa sentidos e práticas afetivas e conjugais vivenciadas por travestis encarceradas em uma penitenciária masculina. São observados os discursos da administração prisional sobre os relacionamentos sexuais e amorosos na Alas LGBT, assim como as narrativas das próprias travestis sobre seus casos e casamentos. Articulando essas duas perspectivas, identifica-se como as conjugalidades são reinventadas e mediadas através do sistema penitenciário. Pensando a prisão como um espaço produtivo de relações, proponho analisar como esses casamentos redimensionam tanto a gramática das relações no contexto da rua como as normas de gênero e sexualidade.

Palauras-chave: Travestis, Prisões, Gênero, Conjugalidades.

\footnotetext{
* Recebido em 07 de janeiro de 2019, aceito em 22 de dezembro de 2020.

** Doutoranda em Ciências Sociais, Universidade Estadual de Campinas (UNICAMP), Campinas, SP, Brasil. vanessasander@gmail.com / http://orcid.org/0000-0002-1825-0097 
Trans women and their husbands in the prison system crisis

\begin{abstract}
This article analyzes meanings and practices of conjugality and affection experienced by trans women imprisoned in a male penitentiary. The discourses of the prison administration on the sexual and loving relationships in the LGBT wings are observed, as well as the trans women's own narratives about their affairs and marriages. Articulating these two perspectives, the paper identifies how conjugalities are reinvented and mediated by the penitentiary system. Thinking of prison as a space that produces relationships, I propose to analyze how these marriages reshape the grammar of relationships in the context of the street, as well as the norms of gender and sexuality.
\end{abstract}

Keywords: Trans women, Prisons, Gender, Conjugalities. 


\section{As bichas e os bofes na crise do sistema penitenciário}

"Desde o começo, as experiências das pessoas, de desejo e raiva, de memória e poder, comunidade e revolta são inflectidas e mediadas pelas instituições através das quais elas encontram seu significado - e que elas, por sua vez, transformam"

(Anne Mcclintock)

A primeira ala específica para pessoas que se reconhecem como travestis e homossexuais em uma instituição penitenciária masculina foi instituída pelo governo do Estado de Minas Gerais em 2009. A unidade em questão possui 754 vagas, mas, segundo dados da Secretaria de Estado e Defesa Social (SEDS), estima-se que ela abrigue 1740 pessoas, dentre elas, os $51^{1}$ detentos e detentas que ocupam a Ala $\mathrm{LGBT}^{2}$ ou Ala Rosa, como o pavilhão 4 da penitenciária também é conhecido. A criação dessa ala específica foi promovida por uma iniciativa do Centro de Referência LGBT de Minas Gerais, em parceria com a Coordenadoria Especial de Políticas de Diversidade Sexual (CODS), após uma série de visitas técnicas às unidades prisionais ${ }^{3}$ (Lamounier, 2018). Dentro de um ano, a ala tornou-se oficialmente uma política do governo estadual, de forma que qualquer pessoa presa que opte por firmar um documento declarando-se homossexual ou travesti no território mineiro é encaminhada para o pavilhão anexo de uma das duas unidades masculinas que possuem alas.

Este trabalho parte de apontamentos etnográficos de minha pesquisa de doutorado, que tem como locus privilegiado uma dessas instituições: uma penitenciária masculina localizada em São Joaquim de Bicas, município da região metropolitana de Belo Horizonte. A partir da análise de algumas cenas e diálogos recolhidos em campo, pretende-se refletir sobre por que, como e onde ocorre esse disparador que faz com que as prisões e toda a malha institucional punitiva ganhem destaque dentro dos pleitos dos movimentos trans; e que também faz com que essa população ganhe proeminência nas produções técnicas de determinados aparelhos de Estado. Além disso, analiso as maneiras pelas quais esses discursos e processos de Estado atravessam as práticas conjugais e afetivas das travestis privadas de liberdade, configurando tramas institucionais complexas (Gregori; Silva, 2000; Rui, 2014).

\section{Separar para proteger}

"Cheguei a sofrer 21 estupros em um dia. Peguei hepatite e sífilis". Essa declaração, atribuída à Vitória Rios, travesti egressa do Presídio de Vespasiano, tornou-se um artefato político importante para construir narrativas sobre a implementação das Alas LGBT. Presenciei tal frase ser repetida no discurso de ativistas trans, estampada em Power Points de funcionários do governo e impressa em reportagens de grandes jornais. Embora não exista uma estatística oficial, a Secretaria do Estado de Defesa Social afirma receber constantemente denúncias de abusos sexuais contra travestis $e$ homossexuais apenados(as). Nesse sentido, os discursos e justificativas em torno da criação dessa política prisional de separação socioespacial funciona através da rememoração e antecipação da violência sexual. A categoria violência mostra-se polissêmica através de seus usos jurídicos,

\footnotetext{
1 Esse número me foi informado pela assistente social da prisão, nos primeiros meses de 2017, quando iniciei o trabalho de campo. Obviamente essa quantia é bastante flutuante, e, em minhas últimas idas a campo, no ano de 2018, ela havia dobrado: cerca de 100 pessoas estavam detidas no Pavilhão 4. As justificativas dos gestores para esse aumento considerável eram sempre articuladas a partir da retórica da crise no sistema, como será explorado mais adiante.

2 O acrônimo LGBT - lésbicas, gays, bissexuais, travestis e transexuais - representa uma cristalização relacionada a uma multiplicidade de redes e organizações, que estão envolvidas na delimitação de identidades e disputas por visibilidade no interior de um movimento no qual o sujeito político se complexifica periodicamente (Facchini, 2005). Atualmente, muitas organizações e ativistas adicionam ainda duas letras e um sinal de adição à sigla, resultando em LGBTQI+, que soma sujeitos queer e intersexo a essa equação. Contudo, adoto aqui o acrônimo LGBT por ser essa a qualificação da Ala usada pelo sistema penitenciário. É importante pontuar também que a própria categoria Presos LGBT ganha corpo nas falas e documentos da administração prisional principalmente nos discursos sobre o destino das travestis e transexuais em cadeias masculinas, tornando-as a face mais visível da temática.

3 Após a implementação de alas específicas, em caráter experimental, nas unidades penitenciárias de Minas Gerais, Rio Grande do Sul e na Paraíba, a Resolução Federal Conjunta n. 1, de 15 de abril de 2014, oficializou a recomendação da criação de Alas para LGBT nas prisões de todo país.
} 
militantes e administrativos, mas tanto secretários de Estado quanto ativistas parecem concordar com uma necessidade de proteção imperativa.

Em entrevista para o portal de jornalismo EBC Notícias ${ }^{4}$, em setembro de 2013, o então subsecretário de administração prisional de Minas Gerais, Murilo Andrade, afirmou que a medida de implementação das alas, acusada de segregatória, possuía caráter de urgência e de prevenção da violência: "A ideia é tirar essas pessoas do convívio dos presos, porque havia denúncias de maus tratos, além da necessidade de oferecer a elas um tratamento apropriado". Por sua vez, a então Coordenadora de Diversidade Sexual do Governo de Minas, Walkíria La Roche, defendeu que o problema era maior, tratando-se de uma questão de saúde, graças ao risco de transmissão de doenças sexualmente transmissíveis, aumentado pela recorrente violência sexual: "É muito comum no nosso país que essas pessoas sejam usadas como moeda de troca nos presídios. Não há preocupação com a transmissão de DST. E como os homens, depois, recebem visita íntima, pode causar uma epidemia". É importante pontuar que o Estado frequentemente mobiliza discursos sobre o estupro nas prisões, vinculando-os ao contágio de Doenças Sexualmente Transmissíveis e a "questões de saúde pública". Além de evidenciar como soropositividade e travestilidades compõem a rede semântica e a carga moral envolvida no modo como é pensada a transmissão do vírus do HIV, é possível perceber, conforme propõe Didier Fassin (2000), como a ideia de saúde pública se constitui através de arranjos discordados, se elaborando de modo cambiante entre a retórica e o pragmatismo ${ }^{5}$.

Ainda que a construção de espaços específicos nos presídios tenha sido, de certa forma, chancelada por movimentos sociais de travestis e transexuais, os discursos da administração prisional sobre sua criação vão menos num sentido de garantia de direitos humanos do que numa vontade de gerir, num sentindo foucaultiano, aquela população que descrevem como causadora de desordem: corpos inclassificáveis que causam desejos incontroláveis. Ao menos foi esse o tom que transpareceu nas falas dos administradores da instituição nos primeiros contatos de negociação da entrada em campo, onde questionaram-me sobre maneiras de colaborar com a gestão $e$ classificação daqueles "corpos exagerados" e dos desejos que provocavam, enfatizando que precisavam "acalmar a situação caótica". Aqui se faz ver uma razão de Estado, para utilizar o léxico de Foucault (2008), cuja racionalidade implica a construção de conjuntos de saberes e de tecnologias de poder que incidem com força especial sobre determinadas populações nos processos de administração da vida cotidiana do sistema prisional.

Por outro lado, os diversos atores do Estado (funcionários de distintos escalões e instituições, dos agentes penitenciários aos secretários do governo) misturam a expressão da necessidade de gerir esses corpos junto a discursos públicos que denunciam os sofrimentos $e$ as frequentes violências sofridas por travestis e homossexuais dentro das penitenciárias, especialmente os casos de violência sexual. Dessa forma, as travestis são colocadas em dois lugares aparentemente paradoxais: o de pessoas promíscuas donas de corpos hipersexualizados que, em alguma medida, justificam as investidas violentas; ou o de vítimas indefesas sem qualquer autonomia sobre seus desejos. Contudo, nas duas visões, o desejo sexual dos demais presos figura como uma força incontrolável, muitas vezes sob a forma de um "instinto natural" sobre o qual os homens têm pouco ou nenhum controle, sobretudo em privação de liberdade. Assim, o isolamento espacial em áreas específicas emerge como a solução capaz de conter impulsos sexuais incontroláveis por corpos "exagerados" que os atiçam. As alas são forjadas como a maneira mais eficaz de controlar relações entre masculinidades agressivas e feminilidades frágeis e, ao mesmo tempo, provocantes.

\footnotetext{
4 Ver notícia "Presídios estão adotando alas LGBT para reduzir casos de violência contra homossexuais", do dia 23/09/2013 [http://www.ebc.com.br/noticias/brasil/2013/09/presidios-estao-adotando-alas-lgbt-para-reduzir-casosdeviolencia-contra - acesso em: 19 set. 2016].

${ }^{5}$ Roberta Canheo (2017) mostra como, nas décadas de 1970 e 1980, a adoção da visita íntima na Lei de Execução Penal foi impulsionada pela tentativa de se prevenir práticas homossexuais/homoeróticas nas prisões. Nas décadas de 80 e 90, a gestão da sexualidade girou em torno de questões sanitárias, e a população $L G B T$ ganhou destaque por causa da disseminação do HIV, sendo considerada como um grupo de risco. Entretanto, a partir principalmente da década de 2010, esse mesmo grupo passou a ser constituído como um sujeito de direitos, e ao mesmo tempo como um grupo em risco.
} 
Nesse sentido, a gestão do contato sexual entre presos aparece, em certos momentos, como um mecanismo que separa um modelo ideal de masculinidade de uma miríade de desviantes morais. $\mathrm{O}$ foco da sensibilidade administrativa oscila entre dois pontos: de um lado, em torno do sexo entre pessoas desigualmente investidas de poder (sobre o qual passa a pairar a sombra da violência presumida), e de outro, em torno daqueles que parecem exercer pouco ou nenhum controle sobre seus próprios impulsos e paixões (Carrara, 2015). Assim, concepções de gênero e sexualidade informam saberes e práticas de Estado: a naturalização de um padrão masculino $e$ heterossexual de punição e a criação de espaços para "outros" que são marcados em termos de gênero e sexualidade (Lago; Zamboni, 2016).

Se durante alguns anos a implementação de Alas LGBT nos presídios de Minas Gerais foi propagandeada como política modelo - servindo inclusive de referência para a gestão penitenciária em todo país -, a situação atual dessa arquitetura institucional me foi apresentada por membros da Secretaria de Estado de Administração Prisional (SEAP) como passando por um momento de desequilíbrio. A "situação caótica" à qual se referiam os administradores foi apontada como o reflexo de uma crise penitenciária mais ampla, que atinge todo o sistema carcerário brasileiro e, ainda que em menor escala, chega também às cadeias mineiras e, consequentemente, às alas LGBT - espaços antes descritos por sua relativa tranquilidade e "ambiente mais feminino", como explicitam suas descascadas paredes rosadas. Para esses atores do Estado, a referenciada crise penitenciária (descrita pela crescente superlotação, infraestrutura precária, contingenciamento de recursos, extinção contratual de funcionários e pelo aumento dos conflitos entre facçóes criminosas e gangs no interior dos presídios) trouxe uma situação peculiar para a Ala Rosa: o acirramento dos conflitos internos na prisão fez com que um número cada vez maior de detentos passasse a se declarar homossexual para aceder às Alas LGBT. Dessa maneira, eles ficam separados do convívio dos demais presos, sem a necessidade de irem para o seguro.

Os seguros são os espaços prisionais destinados àqueles que cometeram atos considerados inaceitáveis pelos outros presos, tais como estupros, desrespeito à visita alheia ou fornecimento de informações para os agentes de segurança. Geralmente são celas ou pavilhões separados do convívio, além de serem espaços conhecidos pelo grande controle dos agentes institucionais e pela precariedade extrema das instalações: é comum que sejam os lugares mais escuros, abafados e fétidos das unidades, como observa Fábio Mallart (2019). Por isso, as alas LGBT eram muitas vezes descritas pelos agentes penitenciários como uma espécie de "seguro soff", ou "seguro maricas". Para lá eram enviados os presos e presas que adotavam expressões de gênero e sexualidade condenáveis para a massa carcerária, mas residindo em espaços descritos como possuidores de infraestrutura menos deficiente que o restante da prisão, com mais vagas, limpeza e não obrigatoriedade do uso do uniforme, o que é muitas vezes descrito retoricamente como "um privilégio", tornando estratégica a assinatura dos documentos que promovem o acesso a essas alas, tendo em vista a crescente precarização e superlotação do sistema carcerário brasileiro ${ }^{6}$. Portanto, a edificação da Ala Rosa enquanto uma espécie de hibrido entre seguro e convívio mostra como essas divisões espaciais, que se mostram também divisões morais, são balizadores imprescindíveis para narrar e descrever a experiência prisional (Marques, 2010).

Assim, foi essa configuração que supostamente alterou o equilíbrio das alas, já que para os gestores penitenciários a chegada desses "homens heterossexuais que se passam por gays ou que usam as travestis" aumentou os conflitos nesses espaços e trouxe a presença de drogas e armas, antes diminuta e relativamente controlada. Além disso, os agentes penitenciários afirmavam constantemente que a presença ostensiva de determinados atributos e corpos masculinos haviam "descaracterizado o projeto".

É curioso notar que, embora fossem referidos pelos funcionários e membros das secretarias como os héteros, ao assumirem relações com travestis e homossexuais, esses detentos costumam

\footnotetext{
${ }^{6}$ Aqui é importante pontuar que, no segundo semestre de 2018, essa situação sofreu uma reviravolta: a ala LGBT começou a receber uma enorme quantidade de transferências e passou a ter lotação ainda maior que os demais pavilhões da unidade. Assim, as justificativas de busca por esses espaços se deslocaram das questões infraestruturais e centraram-se numa narrativa de querela entre administradores prisionais, que tentavam se livrar de seus "presos problemáticos" através de transferências feitas em caráter de urgência sob justificativa de proteção contra a violência sexual.
} 
perder o status ligado à masculinidade perante a massa carcerária, sendo, muitas vezes, considerados como gays e veados, que "desrespeitam a lei do crime, que é pra sujeito homem". Já entre as travestis, eles são chamados de bofes ou mariconas 8 , conforme acionamentos de desejo ou nomeações pejorativas (Pelúcio, 2005). Conforme propõe Mallart (2014), vemos como as relações se redefinem o tempo todo nos embates e nas circunstâncias cotidianas da gestão tensa $e$ conflituosa das penitenciárias, de tal modo que é o próprio universo institucional que se reordena nas suas práticas e nos seus agenciamentos internos, assumindo configurações distintas conforme se deslocam os jogos de poder que aí se processam. Dessa forma, é possível analisar a relação entre as dinâmicas de organização do espaço prisional $e$ as formas de identificação e diferenciação entre presos em termos de gênero e sexualidade (Zamboni, 2017).

A superlotação das alas e os conflitos atribuídos à presença dos héteros criaram impasses para a administração penitenciária e geraram uma série de debates entre os diversos atores envolvidos. De início, a Secretaria de Estado de Administração Prisional aventou que a solução mais simples seria retirar os homens 9 das alas, de modo que travestis e homossexuais tivessem preferência para ocupar as vagas disponíveis nesses espaços. A prioridade seria dada para as travestis, sob a justificativa de que são elas "as mais vulneráveis" e maiores vítimas de transfobia e violência sexual na prisão. Trata-se de um contexto discursivo em que gênero e sexualidade se entrecruzam com a noção de vulnerabilidade, encontrando articulações provisórias na construção de certos sujeitos enquanto vítimas merecedoras da proteção do Estado. Assim, o recurso discursivo à brutalidade atua na compleição identitária do próprio movimento LGBT, ao perfazer suas estratégias e pautas políticas (Efrem Filho, 2016), ao mesmo tempo em que atua também nos processos de materialização das políticas de Estado.

Rumores sobre essas possíveis transferências chegaram ao conhecimento das(os) integrantes da ala LGBT e não foram bem recebidos, gerando uma série de brigas e descontentamentos, conforme me foi descrito por Suzana ${ }^{10}$, travesti que reside na ala há 3 anos.

“- Aqui estando lotado eles quiseram dar preferência pras trans, né? É ala das bichas, das gays, depois dos gays masculinos e depois do resto. E qual foi a solução que apresentaram pra nós? 'Vamos tirar os bofes' [Risos]. Aí a casa caiu. As bichas ficaram loucas, todo mundo causando aqui dentro porque os maridos iam embora. E pronto! Deu briga entre elas de tanto babado que era. E briga de travesti é que nem briga de cachorro grande, não é bonito de ver, não. Briga de faca e tudo teve. E uma ainda veio e cortou o cabelo da outra. Agora você imagina o que é cortar o cabelo de uma travesti. Você é mulher e com esse cabelão sabe o que um picumã ${ }^{11}$ representa pra gente. Ainda mais aqui dentro". ${ }^{12}$

\footnotetext{
7 Em sua etnografia de uma prisão masculina no Estado de São Paulo, sob domínio do Primeiro Comando da Capital (PCC), Karina Biondi (2010) relata que comumente ouvia dos detentos que as bichas e monas da unidade "são do crime, mas não são do crime, porque o crime não dá o cu". Ainda que o crime em Belo Horizonte não tenha o PCC como uma presença hegemônica, sendo caracterizado pela presença de diversos grupos pequenos e fragmentados que se rivalizam mutuamente, esses grupos são capazes de construir uma unidade discursiva que forja um regime normativo próprio (Beraldo, 2020), referido como a lei do crime. E essa lei também prescreve o que é certo nos comportamentos referentes a gênero e sexualidade, valorizando uma virilidade heterossexual.

8 Enquanto o termo bofe está ligado a uma masculinidade desejável, o termo maricona virou uma espécie de xingamento, de ofensa dirigida a certos tipos de homens: aqueles que até passariam por "homens de verdade" na vida pública, mas que na privacidade das práticas sexuais escapariam para o desprestigiado polo feminino. Na tentativa de se invisibilizarem e de negarem publicamente seus desejos, deslocam-se da zona moral da masculinidade: não têm coragem ou honra.

9 Masculinidades e feminilidades são produzidas aqui em articulação e também em contraste, de modo que os homens, bofes, héteros, ou homens de verdade - os detentos da massa carcerária - são tidos como masculinos em oposição ao grupo heterogêneo de bichas, travestis, veados e mulheres de cadeia, tidas como femininas.

${ }^{10}$ Os nomes próprios empregados para designar minhas interlocutoras e interlocutores são ficcionais, com o objetivo de proteger suas identidades. Alguns dos nomes não foram simplesmente trocados, eles representam ficções etnográficas que têm por base a composição de uma variedade de materiais recolhidos em campo, constituindo personagens que misturam acontecimentos e trajetórias.

${ }^{11}$ No pajubá, picumã significa cabelo.

${ }^{12}$ Quando me despedi de Suzana, um agente de penitenciário que havia entreouvido nossa conversa me abordou em seguida e disse: "Antes era a própria prisão que fazia isso. E agora são elas que cortam os cabelos umas das outras. Vai
} 
Além disso, a priorização para alocação das travestis sob a retórica da proteção gerou uma série de dúvidas e obstáculos para os agentes institucionais, visto que os detentos e detentas residentes nas alas - um grupo tão radicalmente heterogêneo - desafia classificações fáceis. Em especial no contexto prisional, é importante notar que as diferenças de gênero são frequentemente pensadas em termos de sexualidade e vice-versa (Lago; Zamboni, 2016). Os termos usados por Suzana já evidenciam: travestis, bichas, gays não são categorias identitárias fechadas e simples de distinguir, mas fazem parte de enunciados contingentes, relacionais e não necessariamente mutuamente excludentes, situados no contexto prisional. Nesse cenário, a separação completa entre identidade de gênero e orientação sexual não parece fazer muito sentido, $e$ as dinâmicas de identificação giram em torno, principalmente, da valorização de certas noções de feminilidade e corporalidades específicas - ainda que não se esgotem em enunciados de gênero e sexualidade $e^{13}$.

Os maridos das travestis eram os personagens mais polêmicos para os atores do Estado: tipicamente viris, eram por vezes classificados como heterossexuais, possíveis fraudes na política das alas. Mas logo surgiam os questionamentos dessa heterossexualidade, visto que se relacionavam com travestis, cuja feminilidade era considerada precária ou falseada; e o embaralhamento e a confusão persistiam. Em mais de uma ocasião, fui abordada pelos próprios maridos, que se mostravam confusos diante da necessidade de designação identitária para acessar direitos. "Então o que eu sou? Homossexual masculino? Bissexual?", perguntavam. Passei algumas semanas em campo curiosa com o uso corrente das categorias homossexual feminino e homossexual masculino, agenciadas amplamente por detentos e detentas quando conversávamos. Posteriormente, descobri que esses eram os únicos termos de identificação possíveis no documento oficial que precisa ser firmado para admissão na ala LGBT. Por isso, as travestis e seus maridos frequentemente se reconheciam assim quando falavam sobre as possibilidades de acesso àqueles espaços. Isso mostra que identidade de gênero e orientação sexual eram categorias misturadas não apenas para os próprios presos, mas também para os papéis da administração penitenciária, refratários à gramática com que os movimentos sociais e mesmo outros setores do governo abordam as temáticas LGBT.

Aqui não me detenho em como processos de documentação, termos de auto declaração $e$ pedidos de transferência - bem como suas assinaturas, carimbos e expedientes burocráticos sustentam e dão materialidade às instâncias estatais (Nadai, 2018). Mas ressalto que é da correlação entre a história institucional da prisão no Brasil e os dilemas impostos aos corpos ali governados que a ala LGBT e seus termos classificatórios, sempre contingentes e instáveis, tornam-se viáveis. Assim, os expedientes que conformam os documentos de autodeclaração de homossexualidade como bens administrativos (Vianna, 2013) evidenciam também o caráter discricionário daqueles que exercem a tarefa de classificar.

Nessa perspectiva, as travestis eram primeiramente identificadas pelos gestores entre aquelas pessoas com os corpos mais transformados. silicone industrial, próteses, cabelos compridos, hormonização avançada. Determinadas corporalidades eram tomadas como preferencialmente violáveis, como se quanto mais evidentes e voluptuosas fossem as formas femininas, mais elas atrairiam os "desejos incontroláveis" dos homens. No entanto, uma série de presas e presos com corpos sem tantas intervenções, mas visivelmente femininos ou andróginos pleiteavam a necessidade de serem mantidos nas alas, fazendo uso estratégico da retórica da necessidade de refúgio espacial contra a violência sexual. Outros detentos que se identificavam como homossexuais e possuíam corpos e performances vistas como masculinas também expressavam a preocupação de serem preteridos na reorganização do espaço e considerados menos urgentes de proteção

entender...". A fala do agente se refere à prática que era (e em muitas unidades ainda é) comum nas penitenciárias de raspar os cabelos das travestis no momento de seu ingresso, da mesma forma que fazem com os demais detentos. Somente a partir de discussões sobre as "necessidades específicas da população LGBT privada de liberdade" que esse costume passou a ser revisto. Também é preciso pontuar, como aponta o trabalho de Natália Lago (2017), que a raspagem de cabelos também acontece como forma de ameaça nas discussões entre mulheres e seus maridos presos, configurando-se como prática possível de cobrança entre os(as) detentos(as).

${ }^{13}$ As categorizações relacionadas a gênero e sexualidade postas em ação no contexto prisional, além de evidenciarem seu caráter contingente e relacional, mostram também íntima articulação com outros eixos de diferenciação, tais como raça, classe e geração, que consubstanciavam diversas categorias que caracterizavam as bichas do pavilhão: as senhoras, as novinhas, as penosas, as tops, as kardashians e as uó. 
"simplesmente por não terem peito". Nesse clima de dúvidas e incertezas, dois maridos de travestis, que se apresentavam com a virilidade característica daqueles considerados autênticos bofes, chegaram a raspar as sobrancelhas de forma bastante desenhada e arqueada, para que a feminilização do rosto os aproximasse das bichas. Nesse manejo de identidades possíveis, entre corpos identificáveis e imensuráveis (Padovani, 2011), vemos como eixos de classificação sempre circunstanciais, contextuais e relacionais são produzidos, objetivados e cristalizados na produção governamental de políticas direcionadas para determinados sujeitos (Aguião, 2014).

Para solucionar as controvérsias geradas pelo possível rearranjo da Ala LGBT, a Coordenadoria de Diversidade Sexual da Secretaria de Direitos Humanos foi acionada pela administração prisional. Seus membros realizaram um par de visitas técnicas nas unidades penitenciárias, às quais trouxeram uma lógica organizada em torno de identidades políticas mais afinadas com os direitos humanos e os movimentos sociais. Assim sendo, cogitaram a possibilidade de transferir as presas travestis e transexuais para os presídios femininos, alegando que essa decisão concordaria com suas identidades de gênero. Ou seja, se identificam-se com o feminino deveriam ser enviadas para as penitenciárias femininas, onde inclusive estariam, supostamente, a salvo da violência sexual. Entretanto, tal possibilidade foi recebida pela maioria das integrantes da ala com um sonoro "Deus me livre!"

As tramas institucionais parecem cada vez mais complexas: as alas progressivamente lotadas tornam-se, para os presos, estratégia de fuga dos conflitos e das dificuldades do convívio. E a ida dos héteros para esses espaços é automaticamente associada ao aumento da presença ostensiva do crime $^{15}$, através do tráfico de drogas e de conflitos violentos. Seus atributos de masculinidade são sempre vinculados à agressividade e "descaracterização do espaço". Ao passo que, se antes o ambiente das alas era descrito como relativamente organizado e "sob controle", articulado à certa domesticidade $e^{16}$ atribuída ao feminino, ele passou a ser considerado uma "bomba relógio", prestes a explodir a qualquer momento. $\mathrm{E}$ as soluções imaginadas pelos agentes institucionais - fossem eles representantes da Segurança Pública ou dos Direitos Humanos - geravam disputas e mobilizavam argumentos discordantes entre as partes do Estado. Enquanto os últimos tentavam entender qual seria o espaço mais adequado para o encarceramento LGBT, seguindo noções cristalizadas de identidade de gênero e orientação sexual, os primeiros reclamavam da impossibilidade de provar a "opção sexual" dos detentos que solicitavam abrigo nas alas. Esse desejo de descobrir uma suposta "verdade" da identidade sexual expressa a preocupação com o resguardo das alas como aparato de proteção contra a violência sexual. Por isso, a inibição de fraudes que possam fragilizar esse instrumento, considerado fundamental para a "garantia de integridade física" de certos sujeitos, acaba por produzir presos LGBT legítimos (e de proteção mais ou menos urgente) e delinear um conjunto de pessoas que não se enquadram nas possibilidades precárias de salvaguarda oferecidas pelas prisões (Lins França, 2017).

A noção de tramas institucionais aqui empregada se refere justamente a essas incompreensões mútuas e desencontros cotidianos da prática dos agentes de Estado e ao campo de forças que esses atores compõem, pautado por disputas e por recursos de poder e legitimidade. Por isso, não é raro que soluções mais efetivas se mostrem muito difíceis de serem alcançadas. Dessa forma, é possível pensar o funcionamento da prisão, e também do próprio Estado, através do sentido processual, performático e figurativo da administração pública (Souza Lima, 2002):

\footnotetext{
${ }^{14}$ Como será discutido mais adiante, a reação de recusa diante da promessa de transferência para as prisões femininas tem a ver com a perda das possibilidades afetivas, sexuais e materiais vivenciadas junto aos detentos nos presídios masculinos. Além disso, muitas das travestis afirmam que as unidades femininas seriam ambientes igualmente hostis, onde também sofreriam com o preconceito.

${ }^{15}$ Conforme proposto por Gabriel Feltran, a expressão "mundo do crime", ou simplesmente "o crime", é tomada aqui em sua acepção nativa, designando o conjunto de códigos e sociabilidades estabelecidas, no âmbito local, em torno da prática de atividades consideradas ilícitas.

${ }^{16}$ Anne McClintock (2010) analisa as relações entre raça, gênero e Imperialismo na Inglaterra vitoriana, mostrando como a força histórica dessas articulações tem implicações persistentes em nosso tempo, como a vinculação entre feminilidade e iconografias da domesticidade. Essa discussão dialoga com os imaginários constantemente afirmados de que atributos de masculinidade convergem com a noção de agressividade enquanto os de feminilidade estariam ligados a passividade.
} 
analisando como certos direitos corporificam certas identidades (e vice-versa) e evidenciando as compreensões imiscuídas em rotinas administrativas de governo (Aguião, 2014).

Além disso, vemos como as tensões, descontentamentos e "brigas de faca" ocorridas no interior das alas despontaram antes mesmo que qualquer medida institucional de reorganização fosse efetivada ou mesmo oficialmente anunciada. Isso mostra a importância de se observar essas sensações de crise enquanto uma criação que gera pânico e sugere comparações entre os grupos e manipulação dos rumores, operando como componente fulcral na reelaboração das narrativas sobre sujeitos, espaços e eventos (Das, 2004). Dialogando com o trabalho de Veena Das, Anelise Gutteres (2016) observa como o rumor calcifica o controle do Estado em determinados territórios marginais, que podem ser as favelas e periferias estudadas pela autora ou as prisões aqui analisadas. Nesses locais, as práticas do Estado figuram através de rumores, representação mimética, obscuridade e poder. Tais práticas se encontram no campo dos ilegalismos do Estado, e adensam os sentimentos de desconfiança, fazendo com que as pessoas envolvidas projetem seus futuros a partir de especulações e sensações de incerteza.

\section{"Travesti na cadeia é sereia": a prisão como possibilidade de afetos}

Visto que muito da minha aproximação com o tema das travestis encarceradas veio, num primeiro momento, por meio dos discursos de Estado e dos movimentos sociais sobre a implementação das Alas LGBT nos presídios, esperava que as narrativas de minhas interlocutoras fossem também centradas no sofrimento e na violência, sobretudo a violência sexual. Mas, para minha surpresa, o assunto para o qual davam destaque $e$ falavam com mais vontade eram os relacionamentos e afetos experienciados nas instituições prisionais: os casos e casamentos vividos em meio ao sofrimento $e$ às violências da experiência do encarceramento. Falo em casos $e$ casamentos não apenas porque eram termos comumente empregados no pavilhão, mas referenciando as reflexões de Natália Padovani (2015a) sobre como as constituições de redes de afeto (enredadas ou não por relações sexuais/ amorosas) são significativas no campo etnográfico no sistema prisional. Nessa perspectiva, afeto, amor e desejo são produzidos pelas práticas de Estado $e$ delas são produtores, porque se emaranham na gestão cotidiana da vida nas prisões, como vemos na cena a seguir:

Iara está sentada em um tapete de pano no canto do pátio, enquanto eu seguro em sua frente um pequeno espelho de moldura laranja. Ela pinça freneticamente as sobrancelhas arqueadas enquanto me conta sobre o longo processo de barganha que teve de enfrentar para conseguir manter aquele espelho na cela, devido à severa restrição de posse de objetos cortantes que se instaurou depois que uma travesti tentou se cortar com uma gilete. Encostada na parede oposta, Janaína lê a bíblia compenetrada. Há apenas dois meses na prisão, Iara relatava com desinibição sua experiência:

Iara: - Eu vou falar uma coisa pra você: a prisão é um lugar horrível. Isso é o óbvio. Mas quando eu cheguei naquela cela na delegacia e me vi ali com vinte homens, todos me olhando, eu confesso pra você que fiquei poderosa. Me achando, me sentindo [Risos]. Na hora de dormir, até deu um pouco de medo, mas eles todos me respeitaram. Mexeram comigo, mas não encostaram um dedo em mim. Aqui não, comigo não, meu amor. Que eu não permito. Depois me mandaram pra cá pra penitenciária e aqui é fácil se arranjar. É igual uma amiga minha falava: travesti na cadeia é sereia, não é, Janaína?

Janaína: - É verdade! Aqui travesti é sereia! E olha que é difícil se manter feminina aqui. Pra isso precisa de recurso, você sabe.

Autora: - Como assim sereia?

Iara: - Sabe aquela coisa dos marinheiros que ficavam todos juntos? Só homem, aquele tanto de homem dias e dias no navio. E daí eles viam as sereias no mar e elas eram a fantasia deles... Aqui é igual! Imagina esse tanto de homem amontoado, uns ficam anos sem encostar numa mulher. E eles veem a gente... Com peito, bunda e cabelo. Então desejam mesmo. Que nem com as sereias, independente do que tem da cintura pra baixo. É por isso que eu consigo me virar aqui. Porque uma coisa que você tem que falar aí na sua pesquisa é que tem muita travesti 
que não recebe visita. Chega dia de visita aqui é só as moscas pra mim. Eu não tenho família. Janaína tem, mas a dela custa a vir. Pra eles não. Vêm as mulheres, que saem de onde Judas perdeu as botas trazer aqué ${ }^{17}$ e comida pros bofes. Então pra mim fica bom assim, porque eu faço um agradinho e eles fortalecem.

Desde minha primeira visita à unidade penitenciária, minhas interlocutoras entusiasmaram-se ao falar das possibilidades sexuais e afetivas vivenciadas na prisão, muitas vezes tratando-as como mais igualitárias, vantajosas $e$ interessantes do que as estabelecidas no fora. Nesse cenário altamente marcado por designações de lugares e práticas tidas como masculinas ou femininas, elas descrevem como são rotineiramente levadas a ocupar posições de prazer e perigo (Vance, 1984). No sistema prisional - estruturado por hierarquias generificadas e sexualizadas -, seus corpos podem ser tanto o alvo preferencial da violência quanto o do afeto e desejo. É comum que a cadeia seja caracterizada por elas, simultaneamente, como "paraíso" e "inferno" pelo mesmo motivo: estarem confinadas junto a centenas de homens.

Iara celebra sentir-se desejada em meio aos detentos e afirma que, apesar de alguns "comentários desrespeitosos", os olhares que recebe encorajam sua autoestima. Sua fala pontua um aspecto importante sobre a arquitetura das alas: elas restringem a interação das travestis $e$ homossexuais com o restante da massa carcerária, estando o convívio possibilitado apenas para aquelas que, como lara, ocupam um dos escassos postos de trabalho externo disponíveis na instituição. Dessa forma, as possibilidades de construir e oficializar um relacionamento afetivo e/ou sexual ficam limitadas a certos espaços e ao constante trânsito dos héteros para a ala. Esse cenário altera as dinâmicas da economia prisional, onde o sustento material $e$ afetivo pode se fazer mediante trocas sexuais. Altera também a relação com a administração da unidade, que constantemente coloca a própria existência e funcionalidade do pavilhão anexo em questão, trazendo a ameaça de seu fim como forma de barganha por "bom comportamento".

Por outro lado, a frase de Janaína sobre a dificuldade de manter-se feminina com poucos recursos revela um aspecto tematizado por elas constantemente: a necessidade de construir $e$ preservar um corpo feminino em um contexto com códigos e limitações particulares. A impossibilidade de acessar hormônios ${ }^{18}$, o uso controlado de vestimentas e a precariedade dos serviços de saúde para lidar com os problemas decorrentes do uso de silicone industrial são reclamações frequentes. Em contrapartida, diante desses problemas emergem práticas de embelezamento improvisadas com materiais improváveis e expressões criativas de feminilidade: a cueca re-costurada como top, o corretivo de caderno que vira esmalte, o tempero convertido em blush, o tecido amarrado como turbante.

Iara metaforiza a figura da sereia como forma de explicitar desejos formados em uma suposta escassez de opções. Como se o confinamento e a concentração de homens em um espaço restrito possibilitassem o florescimento de uma sexualidade intensa e exuberante (Zamboni, 2017). Nessa perspectiva, os homens encontrariam nas travestis o feminino do qual sentem falta frente à impossibilidade de conviver com "mulheres de verdade". Como declara Rebeca: "como não tem amapô $^{19}$, nós, as poucas bichas lá dentro, viramos Gisele Bündchen. Porque somos o que tem disponível ali, não se iluda".

Conheci Rebeca e sua filha, Dandara, durante o campo realizado no mestrado nas pistas de prostituição de travestis ${ }^{20}$. Esses territórios congregam diversas práticas e ilegalismos em seus cotidianos, que ajudam a configurar o seu ordenamento. Por isso, trânsitos entre as pistas e as prisões são movimentos comuns e sobre os quais conversávamos muito, visto que ambas já haviam

\footnotetext{
${ }^{17}$ Aqué significa dinheiro.

${ }^{18}$ Embora a hormonização seja uma parte importante do fazer-se travesti, e ainda que a manutenção dos tratamentos hormonais esteja garantida por Resolução da Secretaria Nacional de Direitos Humanos, é muito raro que as unidades penitenciárias permitam a entrada desses medicamentos para travestis e transexuais.

${ }^{19}$ Significa mulher.

${ }^{20}$ Durante a convivência na pista e nos espaços domésticos, observei uma coisa que parece fundamental nas experiências das travestis: o aprendizado com as outras sobre como se montare buscar a feminilização que caracteriza a transição. Esse aprendizado envolve relações intergeracionais íntimas que acabam por ganhar o status de relações de parentesco eletivas: relações entre mães e filhas (Sander, 2015).
} 
passado por experiências de encarceramento, ainda que em momentos $e$ instituições diferentes. Nessas conversas, os casos e casamentos vividos na prisão também se destacavam em seus relatos. Dandara, inclusive, "arrumou um marido" durante o período de detenção, a quem visita semanalmente.

- É interessante lá dentro porque entre os detentos acho que existe menos preconceito e discriminação pra relacionar com a gente, sabe? Porque eles mesmos passam por isso na sociedade por serem presidiários. Acho que isso faz eles entenderem mais a gente. São mais sinceros, não iludem, se jogam realmente na relação e te veem como ser humano. Muitos dos homens que aqui fora poderiam ter preconceito, lá dentro mantêm caso com a gente, ficam apaixonados e tudo. Até as bichas mais feias e judiadas arrumam marido lá. Por isso que eu vou visitar o meu quase toda semana, sempre que dá eu vou.

Partindo das narrativas de Iara, Janaína, Rebeca e Dandara, podemos pensar a prisão, como propõe Padovani (2015a), como um espaço produtivo de relações, considerando como os vínculos tecidos a partir da experiência prisional modificam as trajetórias de vida das pessoas que tramam redes de conjugalidade e afeto durante a privação de liberdade. Nesse sentido, a prisão torna-se não apenas mediadora das relações, mas impulsionadora. É curioso pensar sobre como a grande maioria dos trabalhos produzidos a partir de prisões masculinas fala pouco sobre as redes de afetos que atravessam o convívio nas instituições penais, e como a proposição de se focar nos amores $e$ afetividades ganha força justamente nas experiências das travestis, que corporificam e vivenciam o que é tido como tipicamente feminino nesses espaços (Boldrin, 2014).

Ao falarem das experiências de conjugalidade e das relações sexuais/amorosas vividas nas prisões, Rebeca e Dandara concordam que a privação de liberdade era um momento privilegiado para viver essas relações, para "arrumar um marido", principalmente em comparação com suas experiências no fora. Em suas falas, o aspecto produtivo dos vínculos tecidos na prisão relacionavase intimamente com a rua, ainda que de forma contrastante. Dandara afirmou que por ser travesti, negra e prostituta, estava acostumada a enfrentar um amplo processo de "objetificação" que atravessa e entrelaça esses três marcadores: os homens com quem se relaciona comumente supõem que ela está sempre disponível para o sexo. E só para isso, já que se essas características a tornam atraente sexualmente, elas também a fazem ser triplamente preterida para as relações públicas $e$ monogâmicas que almejava. Estando muito consciente das densas e tensas articulações entre desejos e hierarquias sociais, ela defendeu que, fora da prisão, ser travesti, negra e prostituta a coloca em situação assimétrica perante os homens com os quais gostaria de se relacionar: sente que está sempre entre a atração objetificante ou a aversão e a possibilidade de rechaço e violência. Em contrapartida, dentro das prisões, os homens estariam mais aptos a enfrentar essas diferenças, visto que, para ela, ao viverem na pele o estigma gerado pelo encarceramento, eles se mostravam mais abertos $e$ as relações pareciam menos hierárquicas. Para Dandara, as desigualdades os aproximavam.

Por outro lado, Rebeca acreditava que a narrativa de Dandara era demasiado romantizada, "muito Alice". Insistiu em mostrar como as relações dos homens com as travestis, no dentro ou no fora, estão sempre atravessadas por interesse. Essa categoria revelou-se central para falar sobre os relacionamentos sexuais e afetivos vividos na prisão e também na rua. Para Rebeca, os homens raramente se apaixonam por uma travesti, de maneira que o caminho mais direto para o coração deles seria pavimentado por dinheiro e bens materiais. No entanto, esse fluxo unidirecional de bens é mais possível nas pistas, onde conseguem renda suficiente para bancar a si mesmas e aos maridos. Para ela, na cadeia, a configuração é outra: sem grandes possibilidades de ser provedora situação comum no fora - o interesse dos homens ao assumirem um relacionamento com ela aconteceria para tirar proveito de suas práticas de cuidado e tarefas domésticas: - "Eles querem a gente de dona de casa. Ou melhor, eles querem a gente de escrava pra ficar na mamata". De fato, é comum que as travestis assumam as funções de manutenção e limpeza das celas, lavem roupas e cozinhem diariamente para os maridos. Assim, é usual que aos homens caiba o sustento e a proteção, enquanto as travestis são orientadas para o cuidado e para as tarefas domésticas. Porém, ainda que as relações de afeto, conjugalidades e amor apareçam inseridas em um circuito ou uma espécie de script atravessado por eixos de diferenciação, tais como gênero e raça, essa configuração 
limita, mas não determina as possibilidades dos vínculos a serem produzidos. As normas de conduta e representações não parecem estáveis ou absolutas, mas estão em um jogo de disputas marcado por múltiplas perspectivas e contínuos deslocamentos ${ }^{21}$.

As percepções de Dandara e Rebeca mostram a ambiguidade presente nos regimes afetivos que envolvem gênero, cuidado, intimidade e trabalho doméstico (Manalansan, 2010). Nesse sentido, embora as tarefas de cuidado possam ser descritas pelas travestis como atividades atraentes, por estarem associadas à possibilidade de performatizar o que é tido como feminino, essas práticas envolvem disposições corporais e emocionais contraditórias: ao mesmo tempo que demonstram desafeição e insatisfação, elas também afirmam orgulho de suportar a feminilizadora rotina do trabalho doméstico. Fica evidente como as relações de cuidado, afeto, interdependência e os fluxos de pessoas, bens e signos através dos muros da prisão estão fortemente marcados por padrões de gênero e sexualidade. Como argumenta Moore (2000), pensar nessas práticas e investimentos não se trata apenas de reconhecer que são uma questão de satisfação emocional, mas de benefícios materiais, sociais e econômicos muito reais que são a retribuição de certas atividades fortemente marcadas por gênero. É por isso que modos de subjetividade e questões de identidade estão ligadas a questões de poder $e$ aos benefícios materiais que podem ser consequência do exercício desse poder. A autora insiste no uso do termo "fantasias de poder", pois a noção de fantasia enfatiza a natureza muitas vezes afetiva e subconsciente do investimento em várias posições de sujeito e nas estratégias necessárias para manter esse investimento.

Retomo ainda o relato de lara, que fala sobre as relações com os bofes como possibilidade de "se virar" na prisão ("eu faço um agradinho e eles fortalecem"). Para ela, a necessidade de fazer um "agradinho" está diretamente vinculada ao abandono familiar vivenciado na penitenciária: é raro que ela e sua amiga recebam visitas. A ausência de visitantes é atribuída a uma sobreposição de estigmas: se tornar-se travesti já engendra rupturas nas relações familiares, tornar-se presidiária termina por interrompê-las. Em contrapartida, grande parte dos homens parece ter uma malha de apoio consolidada no fora, principalmente graças a suas mães e esposas, que atuam intimamente na economia da prisão através das visitas e das mercadorias que trazem. É por intermédio de suas mãos que chegam o jumbo, ou o kit, como são chamadas as sacolas com produtos de higiene pessoal, cigarros e alimentos que complementam os precários bens fornecidos pela prisão.

A redistribuição desses apreciados recursos vindos do fora opera através de um mercado informal complexo. Nessa dinâmica, as travestis comumente se envolvem em trocas de bens e benefícios por favores sexuais. Essas relações recebem diversas nomenclaturas e acionam diferentes sujeitos que constituem vínculos: caso, ajuda, servicinho, prostituição, vício ${ }^{22}$ (Passamani, 2017). Tais vínculos não foram caracterizados por elas como mobilizadores de interesse, mas como "forma de sobreviver". Como argumenta Piscitelli (2011), no marco de relacionamentos sexuais e afetivos, a ajuda é frequentemente trocada por sexo, não necessariamente dissociado de afeto. Essas relações, para minhas interlocutoras, não eram necessariamente vistas como prostituição. Algumas delas as viam como programas, parecidos com o que já faziam na pista, outras como formas de "ganhar um agrado", um "fortalecimento", ou mesmo de construir um possível casamento.

O reconhecimento enquanto trabalho sexual parece ter a ver com as conexões afetivas prévias e com o que se ganha em troca dos favores sexuais: quando recebem em dinheiro, por exemplo, é mais comum falar em prostituição. Assim, se o programa evoca um contrato de serviços, a ajuda, situada em uma dinâmica de intercâmbios hierárquicos, remete a noções de amparo, cuidado e afeto que se expressam em termos de contribuição para a sobrevivência econômica. Portanto, é comum que vínculos mediados por diferentes níveis de ajuda tornem-se casamentos, e os bofes tornem-se maridos a partir dessas trocas.

\footnotetext{
${ }^{21}$ É importante pontuar que alguns agentes institucionais também mobilizaram a categoria interesse para falar sobre os relacionamentos entre travestis e héteros. Nesse caso, porém, os homens seriam interesseiros, porque, supostamente, se relacionam com as travestis apenas para obter acesso às alas e desfrutar de suas "regalias".

${ }^{22}$ Vício ou fazer um vício refere-se ao sexo gratuito. Nas áreas de prostituição, é geralmente visto como uma prática depreciativa, já que uma travesti viciosa é alguém que não sabe separar trabalho de afeto e desejo. Supostamente, a viciosa atrapalha os negócios na pista, porque sai de graça com homens desconhecidos e os deixa mal-acostumados. No contexto prisional, o vício aparece como designação de relacionamentos fugazes motivados apenas pelo prazer.
} 


\section{"Aqui não tem estupro": disputas e debates em torno da violência sexual}

Após ouvir minhas interlocutoras entusiasmadas, discorrendo sobre as possibilidades sexuais $e$ afetivas vivenciadas na prisão, esse cenário me intrigou. Eu me perguntava: onde fica toda aquela violência sexual sobre a qual ouvia falar? Quando fazia questionamentos sobre os estupros e a criação das alas, elas me respondiam: "aqui não tem isso". Quando eu conversava com os agentes penitenciários sobre o assunto, eles também eram enfáticos: "cadeia não tem mais isso". O "mais isso" sugere mudanças num lastro temporal que nenhum deles sabia precisar: dizia respeito a mudanças na administração prisional, mas, principalmente, no proceder, no código de conduta das cadeias, que condena veementemente determinadas violências sexuais entre presos ${ }^{23}$.

Por outro lado, quando conversei com membros da Secretaria de Direitos Humanos, arriscaram outra hipótese para a "ausência" da violência sexual: "elas estão tão vulneráveis que não sabem que certas coisas são estupro". No misto de narrativas que eu ouvia frente a um contexto tão complexo, todas as afirmativas pareciam fazer algum sentido. A violência sexual aparecia de forma mais discreta do que o esperado nas falas de minhas interlocutoras, mas estava ali: figurava como pano de fundo difuso, parte um pouco naturalizada da experiência, em momentos pontuais que se diluíam no decorrer de narrativas românticas ou pertencentes a um passado que já não existe na prisão. E mais que isso: as narrativas de violência envolviam mais os agentes de segurança do que os presos com quem compartilhavam o pavilhão. Quando insistia em perguntar sobre o assunto, os demais presos raramente figuravam nos episódios narrados, mas eram repetidas as histórias sobre violações com o uso de um cassetete durante as revistas, ou sobre um agente que condicionava a entrega do pão do café da manha por uma olhada nos seios desnudos das bichas.

Contudo, os discursos dos movimentos sociais e de certos agentes de Estado que falavam sobre os estupros nas prisões recorriam a uma economia particular de sensibilidade e busca por justiça, em que terminavam defendendo a separação espacial do convívio com os demais presos como medida protetiva mais eficaz. Pensando com o trabalho de Larissa Nadai (2012), tais discursos mobilizam grande comoção pública ao mesmo tempo que produzem diferentes inteligibilidades acerca da violência sexual. Assim, essas narrativas fazem emergir uma série de composições morais sobre o perfil dos personagens envolvidos: as travestis podem ser promíscuas e provocantes $e$, simultaneamente, vítimas absolutas que não sabem identificar o abuso ou são incapazes de consentir, ao passo que os homens presos figuram como uma massa carcerária de "instintos" e desejos incontroláveis. Essas categorizações nunca são contraditórias. Ao contrário disso, são por onde se fazem os processos de gestão dos corpos perigosos/vulneráveis. A caracterização dessas masculinidades é feita a partir de atributos de crime e perigo, não por acaso atributos de masculinidade socialmente articulados a sujeitos presos categorizados como pobres, negros, violentos e agressivos: uma virilidade "monstruosa" e racializada (Padovani, 2017). Enquanto isso, a construção de uma imagem da Ala como um espaço pioneiro de garantia de direitos e até mesmo de concessão de "regalias" invisibiliza muitas das violências perpetradas pela instituição.

Ontem o Transvest ${ }^{24}$ organizou uma celebração para o Dia da Visibilidade Trans na ala. As meninas pediram muito por maquiagem na última vez em que estive lá, antes do natal. Por isso, fizemos uma chamada de doações pelo Facebook. Quando busquei as doações, dois dias antes, uma moça me entregou uma caixa cheia de batons e disse "Essa é pras trans". Me passou outra caixa cheia de absorventes e perguntou: "Essa você pode doar pro feminino?".

Há mais ou menos dois meses um pavilhão de mulheres foi inaugurado no presídio, e ela pediu que eu aproveitasse a viagem pra entregar a caixa de absorventes na unidade. Lembrei

\footnotetext{
${ }^{23}$ Adalton Marques (2010) analisa os diversos discursos e balizas temporais agenciados por detentos nas prisões paulistas, tais como "a época de guerra entre os ladrão", que dizem respeito às narrativas e transformações nos códigos de conduta que pautam a experiência prisional.

${ }^{24}$ O Transvest é um cursinho popular, idealizado e presidido pela professora e ativista trans Duda Salabert, com o qual colaborei como professora de sociologia por dois anos. O projeto pedagógico é destinado às pessoas trans de Belo Horizonte e ocupa um lugar ambivalente de ONG e movimento social no cenário local. Entre suas alunas, a presença de egressas do sistema prisional é expressiva.
} 
imediatamente das provocações de Natália Padovani e tive que perguntar: "elas estão precisando de absorventes lá?". Ao que ela respondeu: "Ah, devem estar. Li na internet que até miolo de pão elas usam na falta de absorvente, sabia?". Eu apenas agradeci e saí me equilibrando com as caixas nas mãos.

Quando cheguei no presídio, entreguei as caixas com as doações para a assistente social responsável pela ala. Ao me verem fazer isso, algumas das presas vieram perguntar o que nós conseguimos arrecadar. Elas estavam especialmente interessadas em batons vermelhos $e$ chapinhas para o cabelo. Conseguimos! Suzana e Mandy saíram felizes. Depois que elas se afastaram, Britney se aproximou. Ela está em Bicas há 2 anos. Britney perguntou se conseguimos doações de absorvente, porque ela estava precisando. $\mathrm{Na}$ hora respondi no automático "Nas doações pro pavilhão 4 não tem absorvente".

Apenas alguns minutos depois, com as mãos desocupadas, eu me perguntei: "porque uma travesti estava pedindo absorvente?". Cheguei perto dela e perguntei. Ela me contou, com uma naturalidade espantosa, que havia sido estuprada alguns dias antes, pelo bofe com quem estava tendo um caso. Agora não me lembro se ela chegou a usar a palavra estupro. Só me recordo dela, de cabeça baixa, dizendo "Ele me forçou e agora eu estou com um sangramento que está sujando tudo. Pessoal da cela não para de me zoar da sujeira". Britney disse pra eu não me preocupar, porque o cara já tinha sido expulso do pavilhão e não havia nada mais a ser feito. Ela insistiu que não formalizássemos nenhum tipo de denúncia e afirmou que já estava bem, quase boa, só não queria manchar as poucas calcinhas que possuía. Disse pra eu não ficar comentando com as outras, me abraçou, agradeceu e saiu (Diário de campo, janeiro de 2018).

Naquele dia, quando fui embora, pedi para que a assistente social levasse um dos pacotinhos de absorvente destinadas ao pavilhão feminino para Britney. Não expliquei nada, mas entendi que ela já sabia. Por muitos dias, esse momento não me saiu da cabeça. As provocações de Padovani (2015b), que citei no diário de campo, diziam respeito à história do "miolo de pão", construída como "calamidade comum": o caso de uma mulher que passou dias detida em uma cela de castigo menstruada e fazendo uso de miolo de pão como absorvente higiênico. Tal caso produziu uma narrativa de vulnerabilidade amplamente acionada pelos agentes das ações humanitárias voltadas para o campo das prisões femininas e impulsionou diversas campanhas de doação de absorventes. Como afirma a autora, mais do que uma realidade ou uma questão central na vida das pessoas presas em penitenciárias femininas, "o miolo de pão" tornou-se um jargão, uma generalização, um argumento político utilizado largamente por parte das pessoas interessadas na produção das "mulheres presas" como sujeitos de uma população vulnerável. Ainda que decorra de um acontecimento real, uma situação de tortura, esse jargão, quando agenciado de forma descontextualizada, lança todo o foco para o "miolo de pão" e para a ausência de absorventes, jogando sombra para tantas outras situações de castigo e violações de direitos que ocorrem nas prisões.

Essa foi uma das narrativas de violência sexual mais explícitas que ouvi durante o trabalho de campo e, por um momento, o estupro deixou o lugar de ausência sempre presente no qual eu o havia colocado e tornou-se escancarado (Veiga, 2018). É impossível não pensar na repetição exaustiva da fala de Vitória Rios, em seus 21 estupros em uma cela e nos seus usos políticos preocupados em produzir calamidades que recaiam sobre a animalização da masculinidade do crime e da vulnerabilidade dos percalços categorizados a partir da feminilidade protegida pelas paredes de um pavilhão anexo. Paredes essas que, ao que tudo indica, acabam não logrando sua missão primordial de proteção contra a violência sexual. A espetacularização moralmente engajada de certos casos de violência sexual acaba atuando como uma forma estratégica de montar realidades corporais e legitimar políticas de governo (Rangel, 2018).

A maneira como vulnerabilidade, consentimento, fragilidade e perigo eram articulados de forma aparentemente paradoxal revelaram que, na realidade, não há contradição entre a gestão dos "corpos exagerados" como elementos capsulares de risco e vulnerabilidade e os acionamentos dos Direitos Humanos por essas práticas de gestão. Antes, são práticas complementares de governo que operam a produção de corpos e espaços precisamente por meio da aparente contradição. Adalton Marques (2018) propõe uma reflexão crítica sobre enunciados que se tornaram consensuais no tema do encarceramento, como a inadequação dos sistemas policial, judiciário e penitenciário 
aos ditames democráticos, ou a validade das tecnologias humanitárias para seu funcionamento adequado. $\mathrm{O}$ autor defende que, na verdade, uma razão democrática e humanista vem sendo construída no interior do sistema carcerário brasileiro desde os anos 1970, tornando-se o motor de sua própria expansão. Nesse cenário, o discurso de humanização das condições carcerárias ganhou seu mais potente vetor na proposta de ampliação de vagas como solução possível para a superlotação. A ala LGBT parece encampar essa mesma tensão constitutiva entre segmentação do espaço prisional e razão humanitária, visto que edifica e constantemente amplia espaços separados para populações específicas como política de humanização do sistema prisional.

\section{Um desfecho provisório}

O desfecho da crise nas alas desenrolou-se nos meses posteriores da seguinte maneira: não tendo encontrado solução simples para a situação dos espaços LGBT, mas alegando a necessidade de "apaziguar" o local, os administradores da instituição transferiram alguns dos héteros. As práticas de transferência e distribuição de presos no sistema penitenciário são muito pouco transparentes, $e$ no caso não foi diferente: alguns dos homens foram retirados da ala, enquanto outros permaneceram. E essas decisões foram tomadas a partir de critérios que me pareceram muito pouco palpáveis. O primeiro deles era o grau de envolvimento com gangs e facçóes criminosas. No entanto, o grau de ligação dos detentos com essas organizações parecia muito difícil de precisar e era construído, sobretudo, em torno de rumores e acusações opacas. O segundo critério - esse de permanência - era a manutenção de relações conjugais que fossem vistas realmente como casamentos pelos funcionários. E o ganho de status matrimonial dessas relações pareceu estar ancorado na valorização da monogamia, demonstração pública de romantismo e afeto, na extensão da relação e, principalmente, no cotidiano doméstico marcado por papéis de gênero estereotipados. O marido de Janaína andava de mãos dadas com ela, e esse foi um argumento apontado para sua manutenção na ala. Essa situação indica, como sugere Judith Butler (2003), a dádiva ambivalente na qual a legitimação do Estado pode se transformar, já que:

ser legitimado é aceitar os termos de legitimação oferecidos e descobrir que o senso público e reconhecível da pessoalidade é fundamentalmente dependente do léxico dessa legitimação. Dessa forma, a delimitação da legitimação ocorrerá somente através de uma exclusão de certo tipo, embora não evidentemente dialética. A esfera da aliança íntima legítima é estabelecida graças a produção e intensificação de zonas de ilegitimidade (Butler, 2003:226).

Essas zonas de ilegitimidade recaíram, especialmente, nas relações que envolvem o que era considerado pelos agentes institucionais como prostituição ou promiscuidade. Trocas sexuais, afetivas e econômicas se misturam de maneiras diversas na prisão, de maneira que é difícil até para as pessoas envolvidas classificar categoricamente quando se trata de trabalho sexual, ajuda, agrado, casamento ou vício. Contudo, o revestimento generificado, romântico e conjugal de certas relações parecia assegurar aos administradores penitenciários e aos agentes de segurança que eles estavam cumprindo suas funções, garantindo que "cadeia não é motel", como repetiram algumas vezes.

É importante pontuar que as próprias bichas também se engajaram nessa gestão institucional da superlotação, colaborando pontualmente com as decisões da administração. "Se chegou aqui, passou uma semana e não demonstrou interesse em relacionar com ninguém, nem pra conversar, é porque é oportunista, não tem nem que estar aqui. Ontem mesmo falei de um ocó que nem falava com as bichas pra um agente e já tiraram ele", contou Janaína. Contudo, quando foram convocadas para colaborar sistematicamente e formalmente com a seleção dos presos que ocupariam a ala LGBT, as bichas se recusaram prontamente: "ninguém quer ser X9 e ficar queimada com o crime".

É possivel perceber que o gerenciamento das prisões é pautado por ambivalências de diferentes tipos de assistência e repressão, cuidado e vigilância, direito e regulação. Se, por um lado, os atores da administração prisional pareciam mais preocupados em definir os casamentos e "relacionamentos de verdade" em oposição à "bagunça" e à "libertinagem", os membros da Secretaria de Direitos Humanos traziam discursos que transformavam as travestis automaticamente em vítimas passivas de um sistema de exploração e dominação masculina, sem formas de agência e 
negociação possíveis nas relações que envolviam trocas sexuais. Assim, a crise nas alas LGBT é como uma ponte para a elaboração analítica de como a produção dos pleitos dos movimentos sociais e das produções políticas, no âmbito da governamentalidade, encontram e tensionam temáticas inerentes aos aparelhos prisionais.

Nesse processo, como aponta Souza Lima (2002), o Estado emerge como uma convergência de múltiplas formas simbólicas e modalidades de ação que, ao mesmo tempo que se forma, se impõe: gesta e gerencia, mas é também gestado e gerido. Essa diversidade de formas estatais - que classificam, convergem e se opõem - também evidencia a relevância do plano representacional do Estado, já que seus artifícios de pluralidade também convivem com sua visão unitária e desencarnada, necessária para o próprio fazer político estatal. O cotidiano da Ala LGBT faz ver justamente como os esforços de vigilância e controle do Estado convivem intimamente com seu caráter pretensamente bem-intencionado, em sua modalidade humanizada, pedagógica e nem por isso desprovida de vontade de domínio (Lugones, 2017). Assim, em sua figura entificada, o Estado perde sua concretude, bem como as cisões, dissensos e contingências que o conformam, nos termos de Philipée Abrams (2006), como uma não-totalidade.

Sergio Carrara (2015) afirma a necessidade de discutir a natureza complexa e heterogênea dos modos de regulação das práticas erótico-sexuais e das expressões de gênero, uma vez que tais modos se consolidam a partir do enfrentamento ou da coalizão de diferentes atores ou forças sociais $e$ refletem representações sociais de natureza muito diversa. Nessa perspectiva, interpelar simultaneamente múltiplas dimensões da gestão social do erótico e do sexual significa explorar a coexistência, por vezes conflitiva, de distintos e muitas vezes contraditórios estilos de regulação moral, compreendidos aqui como conjuntos singulares de técnicas de produção de sujeitos - ou seja, "de pessoas dotadas de certa concepção de si e de certa corporalidade" (p. 325). A partir disso, pensar sobre políticas e práticas da gestão penitenciária abre a possibilidade de abordar a própria noção foucaultiana do dispositivo da sexualidade, indagando sobre suas fissuras, tensões e horizontes de transformação. Para Carrara, as reconfigurações do dispositivo da sexualidade incidiriam também na reacomodação de fronteiras e limites, delineando sujeitos de direitos ou vítimas a serem protegidas pelo Estado e, ao mesmo tempo, redefinindo mecanismos de gestão, controle e criminalização das populações.

Assim, sexualidade e gênero aparecem como espaços privilegiados para regulação e gestão da vida dessas pessoas ao mesmo tempo que se constituem como espaços privilegiados para articulações, negociações e agências. Conforme argumenta Padovani (2015a), se a sexualidade é um dispositivo fundamental de gestão das populações, é também ferramenta de articulação na manutenção da vida. As redes que tramam trocas de afeto, sustento material e relações sexuais são constantemente tensionadas e articuladas perante assimetrias de poder e agenciamentos possíveis.

O lugar ambivalente de desejo e perigo que as travestis ocupam nas malhas do sistema prisional fez com que lara e Janaína se qualificassem como sereias. Essa interpretação alegórica de suas condições enquanto presas tem a ver com a capacidade dessas figuras de confundirem categorias fixas com seus corpos híbridos. As sereias habitam os imaginários populares desde a Antiguidade Clássica, possuindo presença significativa, não apenas literária como também iconográfica. Nas cosmologias afro-indígenas brasileiras as sereias são caboclas, entidades encantadas responsáveis por estabelecer uma conexão entre a orixá das águas, Iemanjá, e seus filhos terrestres. Em consonância com seu status de divindades marinhas - metade mulher, metade peixe - elas fazem alusão a um estado intermediário entre terra e água, assegurando a comunicação entre esses dois mundos (Bittencourt, 2017). As sereias são figuras de densidade mítica lembradas pelo fascínio estético que geram, mas também pela dimensão de perigo do seu canto hipnótico; são uma expressão arquetípica da sedução. Essa ambiguidade também permeia a vida das sereias do pavilhão, que, diante da presença dos homens que ingressavam na Ala LGBT, se definiam como essas entidades aquáticas capazes de desviar os marinheiros - como eram metaforizados os presos com quem se envolviam - de seus caminhos ordinários. Além disso, suas figuras pisciformes podem também ser vistas como possuidoras de algo monstruoso e abjeto, que gera medo e repulsa. Nesse sentido, as sereias que povoam a prisão produzem uma espécie de dimensão mediadora entre oceanos e continentes, trazendo fluidez aos territórios e identidades, deslocando-se em mares 
violentos, desafiando classificações generificadas simples de vítimas e algozes, rejeitando os contornos da "passividade" ou da "inação" (Gregori, 1993). Assim, como sugere McClintock (2010), estamos tratando ao mesmo tempo de violência e poder, mas também de processos de produção de diferenças, fantasias e desejos.

\section{Referências bibliográficas}

ABRAMS, Phillip. Notes on the difficulty of studying the State. In: SHARMA, Aradha-na; GUPTA, Akhil (ed.). The anthropology of the State: a reader. Oxford, Blackwell Publishing, 2006.

AGUIÃO, Silvia. Fazer-se no "Estado": uma etnografia sobre o processo de constituição dos 'LGBT' como sujeitos de direitos no Brasil contemporâneo. Tese (Doutorado em Ciências Sociais), Instituto de Filosofia e Ciências Humanas (IFCH), Universidade Estadual de Campinas (Unicamp), 2014.

BERALDO, Ana. Negociando a vida e a morte: estado, igreja e crime em uma favela em Belo Horizonte. Tese (Doutorado em Sociologia), Centro de Educação e Ciências Humanas, Universidade Federal de São Carlos (UFSCar), 2020.

BIONDI, Karina. Junto e misturado: uma etnografia do PCC. São Paulo, Terceiro Nome/Fapesp, 2010.

BITTENCOURT, Coralina. Pessoas, Sereias e Divindades: um estudo etnológico, mitológico e etnooceanográfico em uma colônia de pescadores no sul do Rio Grande do Sul. Dissertação (Mestrado em Ciências Sociais), Instituto de Ciências Humanas, Universidade Federal de Pelotas (UFPel), 2017.

BOLDRIN, Guilherme. Monas, envolvidos e o crime: etnografia com travestis e homossexuais em uma prisão paulista. Monografia (Graduação em Ciências Sociais), Faculdade de Ciências Sociais, Universidade Federal de São Carlos (UFSCar), 2014.

BUTLER, Judith. O parentesco é sempre tido como heterossexual? cadernos pagu, (22), Campinas-SP, Núcleo de Estudos de Gênero-Pagu/Unicamp, 2003, pp.219-260. [https://www.scielo.br/j/cpa/a/vSbQjDcCG6LCPbJScQNxw3D/?format=pdf\&lang=pt - acesso em: 19 set. 2016].

CANHEO, Roberta. "Puxa pro Evaristo": produção e gestão da população LGBT presa na cidade do Rio de Janeiro. Dissertação (Mestrado em Ciências Jurídicas e Sociais), Universidade Federal Fluminense, Niterói, 2017.

CARRARA, Sérgio. Moralidades, racionalidades e políticas sexuais no Brasil contemporâneo. Mana, 21 (2), Rio de Janeiro, 2015, pp.323-345.

DAS, Veena. The signature of the state: the paradox of illegibility. In: DAS, Veena; POOLE, Debora. Anthropology in the margins of the sate. Oxford, James Currency, 2004, pp. 162-183.

EFREM FILHO, Roberto. Corpos brutalizados: conflitos e materializações nas mortes de LGBT. cadernos pagu, (46), Campinas-SP, Núcleo de Estudos de Gênero-Pagu/Unicamp, 2016, pp.311-340. [https://www.scielo.br/j/cpa/a/3Lg83YcW5D6ZVdtt5KFrx4q/?lang=pt - acesso em: 19 set. 2019].

FACCHINI. Regina. Sopa de letrinhas? Movimento homossexual e produção de identidades coletivas nos anos 90. Rio de Janeiro, Garamond, 2005.

FASSIN, Didier. Comment faire de la santé publique avec des mots. Une rhétorique à l'ouvre. Ruputure, revue transdisciplinaire em santé, v.7, n.1, 2000, pp.58-78.

FELTRAN, Gabriel. Fronteiras de tensão: política e violência nas periferias de São Paulo. São Paulo, Editora Unesp; CEM, Cebrap, 2011.

FONSECA, Claudia; MARICATO, Glaucia. Criando comunidade: emoção, reconhecimento e depoimentos de sofrimento. Interseçôes, 15 (2), Rio de Janeiro, 2013, pp.252-274.

FOUCAULT, Michel. Segurança, território e população. São Paulo, Martins Fontes, 2008.

FRANÇA, Isadora Lins. Refugiados LGBTI: direitos e narrativas entrecruzando gênero, sexualidade e violência. cadernos pagu, (50), Campinas-SP, Núcleo de Estudos de Gênero-Pagu/Unicamp, 2017. [https://www.scielo.br/j/cpa/a/gzz9CBDpLFhVPQ9S9B6nwhn/abstract/?lang=pt - acesso em: 19 set. 2019].

GREGORI, Maria Filomena; SILVA, Catia. Meninos de rua e instituições. São Paulo, Contexto, 2000. 
GREGORI, Maria Filomena. Cenas e queixas: um estudo sobre mulheres, relações violentas e a prática feminista. São Paulo, Paz e Terra / ANPOCS, 1993.

GUTTERRES, Anelise. O rumor e o terror na construção de territórios de vulnerabilidade na zona portuária do Rio de Janeiro. Mana, n.22, Rio de Janeiro, 2016, pp.179-209.

LAGO, Natália. Mulher de preso nunca está sozinha: gênero e violência nas visitas à prisão. Aracê Direitos Humanos em Revista, n. 5, 2017, pp.35-53.

LAGO, Natália; ZAMBONI, Marcio. Políticas sexuais e afetivas da prisão: gênero e sexualidade em contextos de privação de liberdade. In: Anais do $40^{\circ}$ Encontro da ANPOCS, Caxambu, MG, 2016. [https://ns1.anpocs.com/index.php/papers-40-encontro/spg-3/spg13-3/10052-politicas-sexuais-e-afetivasda-previsao-genero-e-sexualidade-em-contextos-de-privacao-de-liberdade/file - acesso em: 19 set. 2019].

LAMOUNIER, Gab. Gêneros encarcerados: uma análise trans.viada da política de Alas LGBT no Sistema Prisional de Minas Gerais. Dissertação (Mestrado em Psicologia Social), Faculdade de Filosofia e Ciências Humanas, Universidade Federal de Minas Gerais (UFMG), Belo Horizonte, 2018.

LUGONES, María Gabriela. ¿Matronato? Gestiones maternales de protección estatal. cadernos pagu (51), Campinas-SP, Núcleo de Estudos de Gênero-Pagu/Unicamp, 2017. [https://www.scielo.br/j/cpa/a/pPgvCpCNGPjh8vXHDfvSC9p/abstract/?lang=es - acesso em: 19 set. 2019].

MALLART, Fábio. Findas linhas: circulações e confinamentos pelos subterrâneos de São Paulo. Tese (Doutorado em Sociologia), Faculdade de Filosofia, Letras e Ciências Humanas, Universidade de São Paulo (USP), São Paulo, 2019.

Cadeias dominadas: a Fundação CASA, suas dinâmicas e as trajetórias dos jovens internos. São Paulo, Terceiro Nome, 2014

MANALANSAN, Martin. F. Servicing the world: Flexible Filipinos and the unsecured life. In: STAIGER, J.; CVETKOVICH, A.; REYNOLDS, A. (ed.). Political emotions. New York, NY, Routledge, 2010, pp.215228.

MARQUES, Adalton. Humanizar e Expandir: uma genealogia da segurança pública em São Paulo. IBCCRIM, 2018.

Crime, proceder, convívio-seguro: um experimento antropológico a partir de relações entre ladrões. Dissertação (Mestrado em Antropologia Social), Faculdade de Filosofia, Letras e Ciências Humanas, Universidade de São Paulo (USP), São Paulo, 2010.

MCCLINTOCK, Anne. Couro Imperial: raça, gênero e sexualidade no embate colonial. Campinas, Editora da Unicamp, 2010. Tradução: Plínio Dentzien.

MOORE, Henrietta. Fantasias de poder e fantasias de identidade: gênero, raça e violência. cadernos pagu (14), Campinas-SP, Núcleo de Estudos de Gênero-Pagu/Unicamp, 2000, pp.49-70.

NADAI, Larissa. Entre pedaços, corpos, técnicas e vestígios: o Instituto Médico Legal e suas tramas. Tese (Doutorado em Ciências Sociais), Instituto de Filosofia e Ciências Humanas, Universidade Estadual de Campinas (Unicamp), 2018.

Descrever crimes, decifrar convenções narrativas: uma etnografia entre documentos oficiais da Delegacia de Defesa da Mulher de Campinas em casos de estupro e atentado violento ao pudor. Dissertação (Mestrado em Antropologia Social), Instituto de Filosofia e Ciências Humanas, Universidade Estadual de Campinas (Unicamp), 2012.

PADOVANI, Natália. Sobre casos e casamentos: afetos e "amores" através de penitenciárias femininas em São Paulo e Barcelona. Tese (Doutorado em Antropologia Social), Instituto de Filosofia e Ciências Humanas, Universidade Estadual de Campinas (Unicamp), 2015a.

Do bandido bananão ao miolo de pão: processos de produção de sofrimento $e$ a violência da vulnerabilidade nas prisões femininas de São Paulo. In: Workshop Governo e Sofrimento, Campinas, 2015b.

No olho do furacão: conjugalidades homossexuais e o direito à visita íntima na Penitenciária Feminina da Capital. cadernos pagu (37), Campinas-SP, Núcleo de Estudos de Gênero-Pagu/Unicamp, 2011, pp.185-218. 
PASSAMANI, Guilherme. É ajuda, não é prostituição: sexualidade, envelhecimento e afeto entre pessoas com condutas homossexuais no Pantanal de Mato Grosso do Sul. cadernos pagu (51), Campinas-SP, Núcleo de Estudos de Gênero-Pagu/Unicamp, 2017. [https://www.scielo.br/j/cpa/a/hvMnXNmpfgsFZRQyG9qSHqH/abstract/?lang=pt - acesso em: 19 set. 2019].

PELÚCIO, Larissa. Na noite nem todos os gatos são pardos: notas sobre a prostituição travesti. cadernos pagu (25), Campinas-SP, Núcleo de Estudos de Gênero-Pagu/Unicamp, 2005, pp.217-248. [https://www.scielo.br/j/cpa/a/5QYynt9X5b35dCjrMcN7npc/abstract/?lang=pt - acesso em: 19 set. 2019].

PISCITELLI, Adriana. Programas e ajuda: intercâmbios econômicos, sexuais e afetivos nos mercados globais do sexo. In. PISCITELLI et. al. Circulaçôes transnacionais: gênero, sexo, afetos e dinheiro. Pagu/Unicamp, 2011, pp.537-582.

RANGEL, Everton. Defendendo o (in)defensável: estupro, luta antimanicomial e Estado. Comunicação oral não publicada apresentada no Workshop Prisóes, Sexualidades, Gênero e Direitos: Desafios e Proposições das Pesquisas Contemporâneas. Universidade Estadual do Rio de Janeiro, 2018.

RUI, Taniele. Nas tramas do crack: etnografia da abjeção. São Paulo, Terceiro Nome, 2014.

SOUZA LIMA, Antônio. Carlos. Gestar e Gerir: estudos para uma antropologia da administração pública no Brasil. Rio de Janeiro, Relume Dumará, 2002.

VANCE, Carol. Pleasure and Danger: Exploring Female Sexuality. Ed. Routledge, New York, 1984.

VEIGA, Cilmara. O caso do Maníaco Matador de Velhinhas: entre trâmites processuais e diferentes formas de narrar que enredam um crime em série. Dissertação (Mestrado em Antropologia Social), Instituto de Filosofia e Ciências Humanas, Universidade Estadual de Campinas (Unicamp), 2018.

VIANNA, Adriana. $O$ fazer e o desfazer dos direitos: experiências etnográficas sobre política, administração e moralidades. Rio de Janeiro, E-Papers. 2013.

ZAMBONI, Marcio. O barraco das monas na cadeia dos coisas: notas etnográficas sobre a diversidade sexual e de gênero no sistema penitenciário. Aracê Direitos Humanos em Revista, n. 5, 2017, pp.93-115.

ZELIZER, V. The purshase of Intimacy, Princeton University Press, 2005. 